\title{
Docetaxel combined with intraperitoneal hyperthermic perfusion chemotherapy and hyperthermia in the treatment of advanced ovarian cancer
}

\author{
TING ZHANG, QIONG PAN, SONGSHU XIAO, LIJIE LI and MIN XUE \\ Department of Obstetrics and Gynecology, The Third Xiangya Hospital \\ of Central South University, Changsha, Hunan 410013, P.R. China \\ Received February 1, 2016; Accepted April 4, 2016
}

DOI: $10.3892 / \mathrm{ol} .2016 .4414$

\begin{abstract}
Ovarian cancer is a clinical type of gynecological malignant tumor with poor prognosis and a high mortality rate. At present, the primary treatment method used is surgery, with chemotherapy as an ajdunctive therapy. Thus, new short-term treatments should be identified. The aim of the present study was to investigate the short-term curative effects and safety of docetaxel combined with intraperitoneal cisplatin chemotherapy and hyperthermia treatment of advanced ovarian cancer. A total of 112 cases of advanced (stage III-IV) ovarian cancer patients confirmed by clinical diagnosis between October 2014 and December 2015 were included in the study. The patients were randomly divided into the study and control groups ( $\mathrm{n}=56$ cases). The control group was treated with docetaxel and intraperitoneal cisplatin hyperthermic perfusion chemotherapy, while the study group was treated with docetaxel venous chemotherapy and intraperitoneal cisplatin cyclical hyperthermic perfusion chemotherapy with BR-TRG-1 body cavity hyperthermic perfusion treatment system. Clinical treatment results for short-term curative effects and adverse reactions were compared and analyzed 8 weeks after treatment. The total effective rate of the study and control groups were 87.5 and $62.5 \%$, respectively, and the difference was statistically significant $(\mathrm{P}<0.05)$. The controlled rate of ascites, remission rate of tumor and descent rate of CA125 of patients in the study group were better than patients in the control group $(\mathrm{P}<0.05)$. The rate of adverse reactions of patients in the study group was $39.3 \%$, and the grade of toxicity was from I to II,
\end{abstract}

Correspondence to: Dr Min Xue, Department of Obstetrics and Gynecology, The Third Xiangya Hospital of Central South University, 128 Tongzipo Road, Changsha, Hunan 410013, P.R. China

E-mail: min_xue_1@163.com

Key words: advanced ovarian cancer, docetaxel, intraperitoneal hyperthermic perfusion, chemotherapy, hyperthermia, combination therapy while the rate of adverse reactions of patients in the control group was $55.4 \%$, and the grade of toxicity was from II to III. The difference between the two groups was statistically significant $(\mathrm{P}<0.05)$. In conclusion, applying the combination of docetaxel, intraperitoneal cisplatin hyperthermic perfusion chemotherapy and hyperthermia to treat advanced ovarian cancer can improve the curative effects with little toxicity; thus, it is worthy of promotion and application.

\section{Introduction}

Ovarian cancer is a common clinical type of gynecological malignant tumor, with a poor prognosis and high mortality. Its concrete etiological factors are unknown, but may be associated with age, procreation, living environment, and emotional factors (1). In recent years, morbidity of ovarian cancer has been on the increase. At present, the main treatment method of ovarian cancer is surgery, but due to effusion in the patients' abdomen, which have biological behaviors of implantation and metastasis, chemotherapy is often used as an adjunctive therapy (2). When the patients of ovarian cancer seek medical assistance, the tumors are already at an advanced stage. The recurrence rate of patients who udnergo initial treatment is high, and the median survival time is approximately 1-2 years after recurrence (3).

The present study aimed to examine the short-term curative effect and safety of combining docetaxel, a type of second-line agent in chemotherapy, as well as hyperthermic intraperitoneal perfusion with cisplatin and thermotherapy for the treatment of patients with advanced ovarian cancer. A total of 112 cases of patients with advanced (stage III-IV) ovarian cancer were examined between October 2014 and December 2015 and comparisons were made of the results yielded.

\section{Materials and methods}

Clinical information. One-hundred and twelve patients with advanced (stage III-IV) ovarian cancer were admitted to the The Third Xiangya Hospital of Central South University between October 2014 and December 2015. Ovarian cancer was confirmed by clinical diagnosis. The patient age range was 
32-74 years, with an average age of $52.5 \pm 4.6$ years. According to FIGO staging criteria, there were 70 cases of stage III, 42 cases of stage IV, 60 cases of serous adenocarcinoma, 22 cases of mucinous carcinoma, 16 cases of endometrioid adenocarcinoma and 14 cases of clear cell carcinoma.

The study subjects who were selected could not undergo surgery, or had recurrence of localized tumor after treatment. CA125 index was elevated, while the routine blood test and hepatic and renal function indices were normal. All 112 cases were confirmed by pathology. The patients were randomly divided into the study and control groups $(n=56$ cases per group). Patient characteristics of the two groups are shown in Table I.

Methods. A new method was used of combining docetaxel and hyperthermic intraperitoneal perfusion with cisplatin in the control group. Briefly, i) docetaxel venous chemotherapy: all 112 cases received $75 \mathrm{mg} / \mathrm{m}^{2}$ docetaxel, injection of $5 \mathrm{mg}$ dexamethasone (Beyotime Institute of Biotechnology, Shanghai, China) intravenously one day prior to chemotherapy, and administered dexamethasone, and palonosetron (Beyotime Institute of Biotechnology) 30 min prior to chemotherapy. This was followed by $30 \mathrm{mg}$ docetaxel injectable powder in $100 \mathrm{ml} \mathrm{5 \%} \mathrm{glucose} \mathrm{as} \mathrm{an} \mathrm{intravenous} \mathrm{drip} \mathrm{and} \mathrm{the}$ patient was observed. If there was no paradoxical reaction, $500 \mathrm{ml} \mathrm{5 \%} \mathrm{glucose} \mathrm{was} \mathrm{added} \mathrm{into} \mathrm{margin.} \mathrm{Severe} \mathrm{hyper-}$ sensitivity reaction was then observed. During the process of intravenous drip, changes of the vital index were monitored closely; and ii) hyperthermic intraperitoneal perfusion with cisplatin: the manner in which abdominocentesis was carried out was dependent on the patient's weight. The patients of medium or lighter weight were punctured at the McBurney's point directly, while overweight or obese patients or who had ascites were given abdominal indwelling catheter and catheterization under the guidance of b-sonography when necessary. The patients with ascites were required to shed them as much as possible before peritoneal perfusion. Then, $60 \mathrm{mg}$ cisplatin was added to 1,500-2,000 $\mathrm{ml}$ physiological saline, and the drip was quickly inserted into the abdominal cavity. The drip was fixed to ensure it was unobstructed, avoiding outleakage of medical liquid, and patient responses were observed. Patients were assisted to alternate posture following perfusion in order that the medical liquid mix sufficiently entered the abdominal cavity.

The combined docetaxel intraperitoneal chemotherapy and BR-TRG-I hyperthermic perfusion intraperitoneal treatment system was used to carry out hyperthermic intraperitoneal perfusion with cisplatin in the study group: i) Docetaxel intraperitoneal chemotherapy was performed in the same way as the control group; ii) BR-TRG-I hyperthermic perfusion intraperitoneal treatment system to carry out hyperthermic intraperitoneal perfusion with cisplatin: during the operation, four abdominal drain tubes were placed in the hepatic zones, spleen, left and right pelvic cavity, respectively. At the beginning of chemotherapy, the patients were in a supine position. Subsequently, 1,500 $\mathrm{ml}$ physiological saline and cisplatin were diluted in $500 \mathrm{ml}$ physiological saline, and connect with BR-TRG-I hyperthermic perfusion intraperitoneal treatment system. Interfaces of the approach and outlet of external circulation were connected with two drain tubes, respectively.
Table I. Patient characteristics of the two groups.

\begin{tabular}{lcc}
\hline Characteristics & $\begin{array}{c}\text { Study group } \\
(\mathrm{n}=56)\end{array}$ & $\begin{array}{c}\text { Control group } \\
(\mathrm{n}=56)\end{array}$ \\
\hline Staging criteria of FIGO & 35 & 35 \\
Stage III & 21 & 21 \\
Stage IV & & \\
Pathology & 30 & 30 \\
Serous adenocarcinoma & 11 & 11 \\
Mucinous carcinoma & 8 & 8 \\
Endometrioid & 7 & 7 \\
adenocarcinoma & & 29 \\
Clear-cell carcinoma & 27 & 27 \\
Ascites & 29 & 31 \\
Yes & & 25 \\
No & 53 & 4 \\
CA125 & 3 & \\
Increase & & \\
Normal & 30 & \\
Localized tumor & 26 & \\
Yes & & \\
No & & \\
\hline
\end{tabular}

The outlet was closed and collateral circulation was initiated. When the temperature reached $37^{\circ} \mathrm{C}$, the valve of the outlet was opened, and when the temperature was steady at $43^{\circ} \mathrm{C}$, cycles of perfusion were carried out for $60 \mathrm{~min}$. Based on the flow speed of the ascites, the speed of the pumping fluid was adjusted in the abdominal cavity, and its general speed was $400-500 \mathrm{ml} / \mathrm{min}$. Perfusate $(800-1,000 \mathrm{ml})$ was left in the abdominal cavity after perfusion was finished. Cisplatin at a dose of $80-100 \mathrm{mg} / \mathrm{m}^{2}$. Based on tolerance and drainage tube patency, the patients were divided equally into groups that had hyperthermic intraperitoneal perfusion 1-3 times, once every other day.

\section{Curative effect valuation standard}

Tumor responses. Evaluation standard of RECIST solid tumor was used to divide tumor responses of patients following treatment into validity and invalidity (4).

Control of ascites. According to the WHO evaluation criteria of clinical effects regarding non-measurable lesions of malignant tumor, we divided the levels of control ascites of patients following treatment into validity and invalidity (5).

According to changes of CA125 of patients after treatment, the clinical curative effects of patients were divided and discriminant criteria of prognosis into validity, stability and invalidity were considered (6).

Short-term curative effect. According to the standard evaluation of malignant tumors following treatment based on WHO, the short-term curative effects of patients in the present study 
Table II. Comparisons of control of ascites, tumor responses and CA125 of patients in the two groups [case (\%)].

\begin{tabular}{lcclccrr}
\hline & \multicolumn{2}{c}{ Study group } & & \multicolumn{2}{c}{ Control group } & \\
\cline { 2 - 3 } Index & Effective cases & Effective rate & & Effective cases & Effective rate & P-value \\
\hline Ascites controlled rate & 21 & $21 / 27(77.8)$ & & 17 & $17 / 29(58.6)$ & $<0.05$ \\
Tumor response rate & 22 & $22 / 30(73.3)$ & & 14 & $14 / 31(45.2)$ & $<0.05$ \\
CA125 descent rate & 45 & $45 / 53(84.9)$ & & 33 & $33 / 52(63.5)$ & $<0.05$ \\
\hline
\end{tabular}

Table III. Comparisons of short-term curative effect in the two groups [case (\%)].

\begin{tabular}{lccccc}
\hline Group & Complete remission & Partial remission & Stability & In progress & Total effective rate \\
\hline Study $(\mathrm{n}=56)$ & $33(58.9)$ & $16(28.6)$ & $4(7.1)$ & $3(5.4)$ & $49(87.5)^{\mathrm{a}}$ \\
Control $(\mathrm{n}=56)$ & $21(37.5)$ & $14(25)$ & $12(21.4)$ & $9(16.1)$ & $35(62.5)$ \\
\hline
\end{tabular}

${ }^{\mathrm{a} C}$ Compared with control group, $\mathrm{P}<0.05$.

were classified as complete remission, partial remission, stability and in progress. Complete remission and partial remission combined were judged as the total effective rate of short-term treatment (7).

Toxicity. The toxicological evaluation was performed according to grading criteria regarding the reaction of anticancer drugs established by WHO (8).

Adverse reaction. The occurrence of nausea, vomit, anemia, leukocytosis, neurotoxicity and other adverse reactions of patients was observed during treatment.

Statistical analysis. Data were statistically analyzed using using SPSS 21.0 software (IBM, Chicago, USA). Comparisons among groups were carried out using the Student's t-test. $\alpha=0.05$ was a significant test level. $\mathrm{P}<0.05$ indicated statistically significant results.

\section{Results}

Comparisons of control of ascites, tumor responses and CA125 of patients in the two groups. Following treatment, the ascites control, tumor response and CA125 descent rates of patients in the study group were improved compared to the control group $(\mathrm{P}<0.05)$ (Table II).

Comparisons of short-term curative effect in the two groups. The total effective rate of the short-term treatment of patients in the study group was $87.5 \%$, while that in the control group was $62.5 \%$. Differences between the two groups were statistically significant $(\mathrm{P}<0.05)$ (Table III).

Comparisons of toxicity and adverse reaction of patients in the two groups. The rate of nausea, vomit, anemia, leukopenia neurotoxicity and other adverse reactions in the study group was $39.3 \%$, and the grade of toxicity was from grade I to grade II, while that of the control group was $55.4 \%$, and grade of toxicity was from grade II to III. The differences between the two groups was statistically significant $(\mathrm{P}<0.05)$ (Table IV).

\section{Discussion}

Ovarian cancer is a type of gynecological malignant tumor with a high mortality rate (1). As the disease does not exhibit specific clinical manifestations, most patients may be at an advanced stage (III to IV) when symptoms become evident leading to loss of treatment time. Thus, the rate of successful treatment is extremely low and only palliative chemotherapy may be utilized to control conditions, relieve or improve patient symptoms, promote life quality as much as possible and prolong survival times.

For advanced ovarian cancer, the standard treatment clinically remains carcinoma cytoreductive surgery followed by intraperitoneal chemotherapy with a combinatorial treatment of platinum and paclitaxel (3).

However, not all patients with advanced ovarian cancer achieve satisfactory clinical results following cytoreductive surgery, and most patients have poor long-term curative effect. Previous studies have shown that dissemination and transfer of ovarian cancer which occur easily are usually biological characteristics that are limited in the abdominopelvic cavity of patients (9). Consequently, intraperitoneal chemotherapy has gradually become a therapeutic approach that is favored by patients with advanced ovarian cancer.

Docetaxel is a type of first-line chemotherapeutic agent that has become widely used. The mechanisms of docetaxel in the treatment of tumors involve the enhancement of tubulin polymerization with the simultaneous inhibition of microtubule depolymerization, and the formation of stable non-functional microtubules that obstruct tumor cell mitosis, leading to an antitumor effect (10).

Previous findings have shown that the concentration of docetaxel is 3-fold that of paclitaxel in tumor cells, and lasts 
Table IV. Comparisons of toxicity and adverse reaction of patients in the two groups.

\begin{tabular}{|c|c|c|c|c|c|c|}
\hline Group & $\begin{array}{l}\text { Grade of } \\
\text { toxicity }\end{array}$ & $\begin{array}{c}\text { Nausea/vomit } \\
\text { n }(\%)\end{array}$ & $\begin{array}{l}\text { Anemia } \\
\mathrm{n}(\%)\end{array}$ & $\begin{array}{l}\text { Leukopenia } \\
\text { n }(\%)\end{array}$ & $\begin{array}{l}\text { Neurotoxicity } \\
\mathrm{n}(\%)\end{array}$ & $\begin{array}{c}\text { Total adverse reaction } \\
\text { rate, } \mathrm{n}(\%)\end{array}$ \\
\hline \multirow[t]{5}{*}{ Study $(\mathrm{n}=56)$} & 0 & $0(0)$ & $0(0)$ & $0(0)$ & $0(0)$ & $0(0)$ \\
\hline & I & $3(5.4)$ & $6(10.7)$ & $2(3.6)$ & $1(1.8)$ & \\
\hline & II & $4(7.1)$ & $3(5.4)$ & $2(3.6)$ & $0(0)$ & \\
\hline & III & $0(0)$ & $0(0)$ & $0(0)$ & $0(0)$ & \\
\hline & IV & $0(0)$ & $0(0)$ & $0(0)$ & $0(0)$ & \\
\hline Total & & $7(12.5)$ & $9(16.1)$ & $5(8.9)$ & $1(1.8)$ & $22(39.3)^{\mathrm{a}}$ \\
\hline \multirow[t]{5}{*}{ Control $(\mathrm{n}=56)$} & 0 & $0(0)$ & $0(0)$ & $0(0)$ & $0(0)$ & $0(0)$ \\
\hline & $\mathrm{I}$ & $0(0)$ & $0(0)$ & $0(0)$ & $0(0)$ & \\
\hline & II & $2(3.6)$ & $2(3.6)$ & $3(5.4)$ & $3(5.4)$ & $10(17.9)$ \\
\hline & III & $5(8.9)$ & $6(10.7)$ & $6(10.7)$ & $4(7.1)$ & $21(37.5)$ \\
\hline & IV & $0(0)$ & $0(0)$ & $0(0)$ & $0(0)$ & $0(0)$ \\
\hline Total & & $7(12.5)$ & $8(14.3)$ & $9(16.1)$ & $7(12.5)$ & $31(55.4)$ \\
\hline
\end{tabular}

${ }^{\mathrm{a} C}$ Compared with control group, $\mathrm{P}<0.05$.

a longer period of time as compared to paclitaxel (10). Thus, compared to paclitaxel, docetaxel has a higher antitumor activity. In addition, the total effective rate for treating ovarian cancer is $73 \%$ when using $75 \mathrm{mg} / \mathrm{m}^{2}$ docetaxel and carboplatin with AUC of 5, and the median survival time of patients following treatment is 18 months, while the overall survival time reaches 24.2 months (11). In a study by Diéras et al, patients with advanced ovarian cancer (stage III to IV) underwent cytoreductive surgery, and were administered chemotherapy using $75 \mathrm{mg} / \mathrm{m}^{2}$ docetaxel and $75 \mathrm{mg} / \mathrm{m}^{2}$ carboplatin, leading to a total effective rate of $58 \%$ (12). Thus, docetaxel and carboplatin are effective in the treatment of advanced ovarian cancer and can be used as first-line treatment in clinical chemotherapy of patients with advanced ovarian cancer.

The treatment effect of abdominal malignant tumor is closely associated with peritoneal metastasis. By controlling peritoneal metastasis, the long-term survival rate of patients can be prolonged and their quality of life can be improved effectively (13). How to control the peritoneal metastasis of patients with abdominal malignant tumor effectively is an important issue, and a challenge regarding the clinical treatment of tumor. In addition, intraperitoneal hyperthermic perfusion chemotherapy is applied after abdominal cavity malignant tumor surgery, which eliminates the subclinical lesions of patients following treatment, removes malignant ascites effectively and prolongs the 5-year survival of patients with advanced ovarian and gastric cancer, which may lead to abdominal cavity implantation metastasis (14). The effective rate of the clinical treatment of malignant ascites can reach $90 \%$.

The clinical application and promotion of intraperitoneal hyperthermic perfusion chemotherapy has been employed in certain medical institutions in America and Spain, France, Italy and Britain as the standard treatment clinically for abdomen malignant tumor. Australia has also promoted the development of intraperitoneal hyperthermic perfusion chemotherapy (15-17).
In China intraperitoneal hyperthermic perfusion chemotherapy has been used in the treatment of abdomen malignant tumor as well as advanced ovarian cancer (since 2004), with good results (18). The present findings have shown that the total effective rate of patients with advanced ovarian cancer in the study group was $87.5 \%$, while that in the control group was $62.5 \%$. The differences between the two groups were statistically significant $(\mathrm{P}<0.05)$.

In general, medical therapy units in China that carry out intraperitoneal hyperthermic perfusion chemotherapy are in the primary stage, medical technology requires improvement, manufacturing technology of medical equipment is difficult, accuracy of temperature control is not high, and perfusion speed of peritoneal cavity fluid is not steady, making it difficult to achieve optimal curative effect of intraperitoneal hyperthermic perfusion chemotherapy (18). The BR-TRG-I hyperthermic perfusion intraperitoneal treatment system, used by our hospital, has high accuracy, its temperature measurement accuracy and temperature controlling precision can reach \pm 0.1 and $\pm 0.2^{\circ} \mathrm{C}$, respectively, and perfusion speed is more stable, and is within $5 \%$ accuracy. It is arguable that automatic control technique of this system is comparable to an international advanced level and can provide good protection insurance of medical equipment for patients with advanced ovarian cancer (18).

Localized temperature a patient's abdominal cavity can reach $43^{\circ} \mathrm{C}$ following treatment of intraperitoneal hyperthermic perfusion chemotherapy. Tumor cells are damaged irreversibly under conditions of high temperatures $\left(43^{\circ} \mathrm{C}\right)$ that last $1 \mathrm{~h}$ (18). After heating, the $\mathrm{pH}$ value of tumor tissues may decrease, leading to dyspoiesis of nucleic acid in vivo, which promotes tumor cell apoptosis. However, normal tissues of the human body are not affected by high temperatures of $43^{\circ} \mathrm{C}$. Generally, normal tissues can tolerate high temperature conditions of $47^{\circ} \mathrm{C}$ for $>1 \mathrm{~h}(19)$.

Thus, intraperitoneal hyperthermic perfusion chemotherapy can kill cancer cells selectively, but does not affect 
normal tissues of the human body. Compared with traditional intravenous chemotherapy, the administration route of intraperitoneal chemotherapy also improves the concentration of anticarcinogens in the abdominal cavity and improves the time of direct reaction between anticarcinogens and tumor cells (18). At the same time, because anticarcinogen reflows to the hepatic system through the portal vein system and enters the systemic circulation after hepatic metabolism, it has few systemic side effects for patients.

Cisplatin belongs to typical drugs of intraperitoneal chemotherapy and clinical antitumor drugs of first-generation platinum (12). This drug mainly acts on purines and the pyrimidine base of DNA in the human body. It can constitute the interlocking of intrachain and interchain DNA in human body which damages DNA functions, obstructs DNA replication and inhibits DNA to synthesize effectively. A high concentration of cisplatin can also obstruct synthesis of RNA and protein (12). Effective concentration of cisplatin in the human body has a lasting effect, and can be maintain over a long period of time in vivo (12). It has difficulty of passing the barrier of peritoneum, thus, the concentration of cisplatin in peritoneum is higher than that of plasma.

Cisplatin is a type of antineoplastic clinical drug without threshold effect (20). Heat treatment can promote the combination of DNA of human cells and cisplatin, which allows the concentration of cisplatin reaching tumor cells to increase and inhibits the restoration of cells to themselves after cisplatin drug acts on the tumor cells.

A combination of cisplatin and heat treatment has synergistic effects. Thus, cisplatin is an optimal anticancer drug for intraperitoneal hyperthermic perfusion (12). The present study used cisplatin as an anticancer drug for intraperitoneal hyperthermic perfusion. The results obtained showed that the rate of adverse reactions in the study group was $39.3 \%$ and the grade of toxicity was from grade I to II, while the rate of adverse reactions in the control group was $55.4 \%$ and the grade of toxicity was from II to III. The differences between the two groups were statistically significant $(\mathrm{P}<0.05)$. Thus, a combination of docetaxel intraperitoneal chemotherapy and BR-TRG-I hyperthermic perfusion intraperitoneal treatment system to carry out hyperthermic intraperitoneal perfusion with cisplatin while treating patients with advanced ovarian cancer has low toxicity and little adverse reactions.

Malignant ascites is a common and main complication of patients with advanced ovarian cancer. Once this complication occurs, it induces renal failure, leading to blockage of cardiopulmonary functions, seriously affecting survival and quality of life for patients, which deteriorates the conditions of patients to a large extent (15).

The majority of treatments for malignant effusion involved repeated paracentesis. Although this treatment rapidly relieves the symptoms of patients, ascites in the abdominal cavity gather together rapidly and form a vicious circle, which leads to ineffective treatment and accelerates mortality (15).

Use of BR-TRG-I hyperthermic perfusion intraperitoneal treatment system to carry out hyperthermic intraperitoneal perfusion with cisplatin while treating, which can effectively reduce the accumulation of ascites in the abdominal cavity of patients, resulting in the treatment of malignant ascites is considerable. The control rate of hydrothorax and ascites can be improved by hyperthermic perfusion and the control level can reach $80 \%$ (21). The results of the present study have shown that the ascites control and tumor response rates in the study group were improved as compared to the control group $(\mathrm{P}<0.05)$, confirming that it is effective and practical to utilize BR-TRG-I hyperthermic perfusion intraperitoneal treatment system to carry out hyperthermic intraperitoneal perfusion with cisplatin while treating patients with advanced ovarian cancer accompanied with ascites.

CA125 belongs to the glycoprotein antigens. It is an important ovarian cancer-associated antigen used to diagnose ovarian cancer and evaluate the clinical effects of ovarian cancer (22). Our findings have shown that the CA125 descent rate of patients in the study group was better than that of the control group $(\mathrm{P}<0.05)$. Thus, use of BR-TRG-I hyperthermic perfusion intraperitoneal treatment system to carry out hyperthermic intraperitoneal perfusion with cisplatin while treating patietns with advanced ovarian cancer can decrease level of CA125 effectively.

In conclusion, the combination of docetaxel, hyperthermic intraperitoneal perfusion with cisplatin and thermotherapy while treating patients with advanced ovarian cancer clinically can improve the short-term curative effect of patients and relief toxicity of patients. Clinically, patients can be administered hyperthermic perfusion 1-3 times for each treatment, and increased treatment times indicate that the short-term curative effect of advanced ovarian cancer is likely to be improved. Since 2014, our hospital has employed intraperitoneal hyperthermic perfusion chemotherapy to carry out hyperthermic intraperitoneal perfusion with cisplatin. The results suggest that 3- and 5-year survival time of the subjects require follow-up observation. A limitation of the study was that the sample size was small. Thus, large-scale investigations are needed to conduct prospective clinical studies to verify the results obtained in the present study.

\section{References}

1. Miyashiro I, Furukawa H, Sasako M, Yamamoto S, Nashimoto A, Nakajima T, Kinoshita T, Kobayashi O and Arai K; Gastric Cancer Surgical Study Group in the Japan Clinical Oncology Group: Randomized clinical trial of adjuvant chemotherapy with intraperitoneal and intravenous cisplatin followed by oral fluorouracil (UFT) in serosa-positive gastric cancer versus curative resection alone: final results of the Japan Clinical Oncology Group trial JCOG9206-2. Gastric Cancer 14: 212-218, 2011.

2. Emoto S, Kitayama J, Ishigami H, Yamaguchi $\mathrm{H}$ and Watanabe T: Clinical significance of cytological status of peritoneal lavage fluid during intraperitoneal chemotherapy for gastric cancer with overt peritoneal dissemination. Ann Surg Oncol 22: 780-786, 2015.

3. Chua TC, Morris DL, Saxena A, Esquivel J, Liauw W, Doerfer J, Germer CT, Kerscher AG and Pelz JO: Influence of modern systemic therapies as adjunct to cytoreduction and perioperative intraperitoneal chemotherapy for patients with colorectal peritoneal carcinomatosis: a multicenter study. Ann Surg Oncol 18: 1560-1567, 2011.

4. Elias D, Gilly F, Boutitie F, Quenet F, Bereder JM, Mansvelt B, Lorimier G, Dubè P and Glehen O: Peritoneal colorectal carcinomatosis treated with surgery and perioperative intraperitoneal chemotherapy: retrospective analysis of 523 patients from a multicentric French study. J Clin Oncol 28: 63-68, 2010.

5. Ishigami H, Kitayama J, Kaisaki S, Hidemura A, Kato M, Otani K, Kamei T, Soma D, Miyato H, Yamashita H, et al: Phase II study of weekly intravenous and intraperitoneal paclitaxel combined with S-1 for advanced gastric cancer with peritoneal metastasis. Ann Oncol 21: 67-70, 2010. 
6. Elias D, Glehen O, Pocard M, Quenet F, Goéré D, Arvieux C, Rat P and Gilly F; Association Française de Chirurgie: A comparative study of complete cytoreductive surgery plus intraperitoneal chemotherapy to treat peritoneal dissemination from colon, rectum, small bowel, and nonpseudomyxoma appendix. Ann Surg 251: 896-901, 2010.

7. Yang XJ, Huang CQ, Suo T, Mei LJ, Yang GL, Cheng FL, Zhou YF, Xiong B, Yonemura Y and Li Y: Cytoreductive surgery and hyperthermic intraperitoneal chemotherapy improves survival of patients with peritoneal carcinomatosis from gastric cancer: final results of a phase III randomized clinical trial. Ann Surg Oncol 18: 1575-1581, 2011.

8. Kapala M, Meterissian S and Schricker T: Neuraxial anesthesia and intraoperative bilevel positive airway pressure in a patient with severe chronic obstructive pulmonary disease and obstructive sleep apnea undergoing elective sigmoid resection. Reg Anesth Pain Med 34: 69-71, 2009.

9. Chua TC, Morris DL and Esquivel J: Impact of the peritoneal surface disease severity score on survival in patients with colorectal cancer peritoneal carcinomatosis undergoing complete cytoreduction and hyperthermic intraperitoneal chemotherapy. Ann Surg Oncol 17: 1330-1336, 2010.

10. Yamaguchi H, Kitayama J, Ishigami H, Emoto S, Yamashita $H$ and Watanabe T: A phase 2 trial of intravenous and intraperitoneal paclitaxel combined with S-1 for treatment of gastric cancer with macroscopic peritoneal metastasis. Cancer 119: 3354-3358, 2013.

11. Franko J, Ibrahim Z, Gusani NJ, Holtzman MP, Bartlett DL and Zeh HJ III: Cytoreductive surgery and hyperthermic intraperitoneal chemoperfusion versus systemic chemotherapy alone for colorectal peritoneal carcinomatosis. Cancer 116: 3756-3762, 2010.

12. Diéras V, Guastalla JP, Ferrero JM, Curé H, Weber B, Winckel P, Lortholary A, Mayer F, Paraiso D, Magherini E, et al: A multicenter phase II study of cisplatin and docetaxel (Taxotere) in the first-line treatment of advanced ovarian cancer: A GINECO study. Cancer Chemother Pharmacol 53: 489-495, 2004.

13. Kitayama J, Ishigami $\mathrm{H}$, Yamaguchi $\mathrm{H}$ and Watanabe T: Salvage gastrectomy after intravenous and intraperitoneal paclitaxel (PTX) combined with oral tegafur/gimeracil/oteracil potassium (S-1) for gastric cancer with peritoneal metastasis. Eur J Surg Oncol 40: S34, 2014.
14. Lee AW, Tyrer JP, Doherty JA, Stram DA, Kupryjanczyk J, Dansonka-Mieszkowska A, Plisiecka-Halasa J, Spiewankiewicz B, Myers EJ, Chenevix-Trench G, et al; Australian Cancer Study (Ovarian Cancer); Australian Ovarian Cancer Study Group: Evaluating the ovarian cancer gonadotropin hypothesis: a candidate gene study. Gynecol Oncol 136: 542-548, 2015.

15. Che YL, Luo SJ, Li G, Cheng M, Gao YM, Li XM, Dai JM, $\mathrm{He} \mathrm{H}$, Wang J, Peng HJ, et al: The C3G/Rap1 pathway promotes secretion of MMP-2 and MMP-9 and is involved in serous ovarian cancer metastasis. Cancer Lett 359: 241-249, 2015.

16. Hung SW, Marrache S, Cummins S, Bhutia YD, Mody H, Hooks SB, Dhar S and Govindarajan R: Defective hCNT1 transport contributes to gemcitabine chemoresistance in ovarian cancer subtypes: overcoming transport defects using a nanoparticle approach. Cancer Lett 359: 233-240, 2015.

17. Wang J, Yang H, Li W, Xu H, Yang X and Gan L: Thioredoxin 1 upregulates FOXO1 transcriptional activity in drug resistance in ovarian cancer cells. Biochim Biophys Acta 1852: 395-405, 2015.

18. Bakrin N, Classe JM, Pomel C, Gouy S, Chene G and Glehen O: Hyperthermic intraperitoneal chemotherapy (HIPEC) in ovarian cancer. J Visc Surg 151: 347-353, 2014.

19. Helm CW: Current status and future directions of cytoreductive surgery and hyperthermic intraperitoneal chemotherapy in the treatment of ovarian cancer. Surg Oncol Clin N Am 21: 645-663, 2012.

20. Parson EN, Lentz S, Russell G, Shen P, Levine EA and Stewart JH IV: Outcomes after cytoreductive surgery and hyperthermic intraperitoneal chemotherapy for peritoneal surface dissemination from ovarian neoplasms. Am J Surg 202: 481-486, 2011.

21. Ohashi N, Jinno S, Kobayashi D, Tanaka C, Yamada S, Fujii T, Nomoto S, Fujiwara M, Takeda S and Kodera Y: Intravenous and intraperitoneal paclitaxel combined with S-1 for advanced gastric cancer with peritoneal metastasis. Nihon Shokaki Geka Gakkai Zasshi 45: 1137-1143, 2012 (In Japanese).

22. Gupta D and Lis CG: Role of CA125 in predicting ovarian cancer survival - a review of the epidemiological literature. J Ovarian Res 2: 13, 2009. 